\title{
IMPRESSÕES RUSSAS DA MODERNIDADE: DOSTOIÉVSKI EM VIAGEM PELA EUROPA
}

\author{
Paulo Mendonça* \\ Universidade Federal Fluminense
}

Resumo: No presente ensaio, analiso o texto não ficcional que Fiódor Dostoiévski (18211881) escreveu ao longo de suas viagens pela Europa em 1862, Notas de inverno sobre impressões de verão (1863) - obra de caráter aparentemente despretensioso e que não obedece ao rigor formal de nenhum gênero literário específico. Em princípio e de forma breve, importa-me destacar a origem da palavra modernidade à luz da investigação etimológica do termo empreendida pelo teórico alemão Hans Robert Jauss (1921-1997) e da concepção elaborada pelo poeta e crítico francês Charles Baudelaire (1821-1867), especialmente em seu poema À une passante. Em seguida, alguns dos principais trechos de Notas de inverno... referentes às descrições físicas das cidades serão comentados de modo a pôr em evidência, sobretudo, o olhar crítico com o qual Dostoiévski observava as transformações pelas quais passava a Europa (notadamente as capitais Paris e Londres) durante a segunda metade do século XIX.

Palavras-chave: Dostoiévski. Modernidade. Europa.

$\mathrm{Na}$ extensa bibliografia crítica sobre a obra de Fiódor Dostoiévski (1821-1881), pouca atenção se dá a um texto não ficcional de sua autoria escrito durante a primeira viagem que o escritor russo fez pela Europa na década de 1860, mais precisamente durante o verão de 1862. Notas de inverno sobre impressões de verão (1863), embora não apresente a genialidade do Dostoiévski romancista, merece a atenção daqueles que estiverem interessados em um olhar crítico acerca do desenvolvimento urbano-cultural de algumas das principais cidades europeias do século XIX. Trata-se de um período de grande importância para o entendimento do conceito de modernidade, que seria elaborado e utilizado pela primeira vez pelo poeta e crítico francês Charles Baudelaire (1821-1867). Aliás, antes de nos debruçarmos nas anotações de Dostoiévski que constituem as Notas de inverno..., é fundamental que elucidemos brevemente qual era a visão de Baudelaire a respeito do próprio sentido da

Esta obra está licenciada sob uma Creative Commons - Atribuição 4.0

\footnotetext{
* Mestre em Estudos de Literatura pela Universidade Federal Fluminense e graduado em Letras, Português e Literaturas, pela mesma instituição. Contemplado com a Bolsa de Excelência Acadêmica da UFF em 2015, estudou Língua Francesa e Literaturas Francófonas na Université de Sherbrooke (Québec - Canadá). Atualmente, cursa sua segunda graduação em Letras, Português/Francês, e participa do grupo de pesquisa "Leitura, Literatura e Formação do Leitor" (UFF). E-mail: <paulo_plana@hotmail.com>.
}

Anu. Lit., Florianópolis, v. 21, n. 1, p. 70-80, 2016. ISSNe 2175-7917 
palavra modernidade. Afinal, o que Dostoiévski observa pelas cidades que passa, sobretudo Paris e Londres, é o surgimento de novas metrópoles em que coexistem beleza e uma inexplicável desordem - características essas tão caras à noção prosaica de modernidade que se costuma atribuir às capitais do século XXI.

A modernidade só pode ser entendida enquanto conceito se nos ativermos à etimologia do termo original. Como percebe Hans Robert Jauss, a palavra latina modernus, cuja origem remonta ao século $\mathrm{V}$, não significa somente o novo, mas também o atual, o que nos permite relacioná-la ao neologismo francês modernité, em que o sentido de transitoriedade (mode) significará exatamente a renovação, a atualidade relacionada a algo perene (éternité). Essa é a definição paradoxal que Baudelaire busca pôr em evidência. Para ele, a modernidade é o atual, sim, mas não somente na acepção latina do termo. Trata-se de uma atualidade em que também podemos enxergar o eterno, o extremo oposto do efêmero; em outras palavras: o clássico. Em um dos poemas mais conhecidos de Les fleurs du mal (1857), "À une passante", o poeta francês apresenta, em versos, de maneira metafórica, o conceito de que estamos tratando: "La rue assourdissante autour de moi hurlait. / Longue, mince, en grand deuil, douleur majestueuse, / Une femme passa, d'une main fastueuse / Soulevant, balançant le feston et l'ourlet; / Agile et noble, avec sa jambe de statue" (BAUDELAIRE, 2011, p. 88) ${ }^{1}$. Embora fugaz, a mulher inominável à qual o poema faz referência tem como uma de suas características marcantes a perna de estátua (clássica?), que representaria, simbolicamente, a antiguidade, isto é, o passado de que a modernidade também se constitui. Portanto, moderno seria aquilo capaz de conjugar os dois extremos: o antigo e o novo.

Voltemos a décadas passadas, mais precisamente a uma ou duas gerações anteriores à de Baudelaire. Nelas, entreveremos reminiscências do que se entende hoje por modernidade. Em especial, interessa-me destacar a ruptura experimentada pela sociedade ocidental a partir da Revolução Francesa. Senão, vejamos: "La Revolution a rompu le fil entre présent et passé. La société moderne est séparée de L’Ancien Régime non seulement par une constitution nouvelle, des habitudes de vie et des idées différentes, mais aussi par un autre goût, une autre relation à la beauté" (JAUSS, 1978, p. 196)². O crítico alemão Hans Robert Jauss (1921-1997) chama atenção para o fato de que a ruptura não se verificou apenas no âmbito político-social,

\footnotetext{
${ }^{1}$ A rua em torno era um frenético alarido. / Toda de luto, alta e sutil, dor majestosa, / Uma mulher passou, com sua mão suntuosa / Erguendo e sacudindo a barra do vestido. / Pernas de estátua, era-lhe a imagem nobre e fina. (Tradução de Ivan Junqueira).

${ }^{2}$ A Revolução rompeu a linha entre presente e passado. A sociedade moderna separa-se do Ancien Régime não apenas por uma nova constituição, hábitos de vida e ideias diferentes, mas também por um outro gosto, uma nova relação com a beleza (Tradução livre).
}

Anu. Lit., Florianópolis, v. 21, n. 1, p. 70-80, 2016. ISSNe 2175-7917 
mas também no estético. Afinal, uma revolução, como é sabido, é motivada por reivindicações de diversas ordens. Dessa forma, estabeleceram-se, desde a negação do Ancien Régime, novas relações entre o homem e as artes. Em outras palavras, a partir de um dado momento, novas concepções no âmbito artístico puderam se configurar. O neoclassicismo deu lugar ao romantismo, que pôde, à época, representar os hábitos de uma sociedade que leu inúmeros romances como se estivesse diante de um espelho, reconhecendo-se nas obras lidas e, por conseguinte, identificando-se com o mundo da ficção. A literatura era percebida, pois, como o atual, ainda que a relação entre os artistas das letras e seus admiradores não fosse de todo harmoniosa. Escritores como Stendhal (1783-1842), para citar apenas um dentre tantos exemplos, souberam expor em suas obras os costumes nem sempre louváveis de uma sociedade pequeno-burguesa da qual o herói literário ambicionava fazer parte. Vide $O$ vermelho e o negro.

Não podemos saber se Dostoiévski compreendia aquilo que observava em suas viagens como a ascensão da modernidade, pois é quase impossível lançar um olhar preciso e consciente sobre o próprio tempo em que vivemos. De toda forma, na condição de estrangeiro, o escritor russo não estava alheio às novidades e às transformações, que ele pôde identificar exatamente por encontrar-se fora de seu "habitat natural". No primeiro dos sete capítulos em que se subdividem as suas notas, "Em lugar de prefácio”, já é curioso observar o tom irônico com que Dostoiévski trata o próprio trabalho que terá a seguir: "Quem de nós, russos (pelo menos dos que leem revistas), não conhece a Europa duas vezes melhor que a Rússia?” (DOSTOIÉVSKI, 2011, p. 69). Escrever impressões sobre as cidades europeias seria algo quase inútil, porquanto todos os russos já possuiriam largo conhecimento sobre o assunto. Continua Dostoiévski: “... nada tenho de especial para contar, e ainda menos para anotar ordenadamente, pois nada vi em ordem, e, se cheguei a ver algo, não tive tempo de examiná-lo" (DOSTOIÉVSKI, 2011, p. 69). Ao afirmar que nada viu em ordem, o escritor chama atenção para o caráter despretensioso de suas anotações, que seriam diametralmente opostas a uma observação científica, fundamentada em bases sólidas (o que justifica o uso do termo "impressões" no título da obra em questão). As notas não têm compromisso algum com a investigação formal de um expedicionário, o que, nesse caso específico, parece ser algo positivo, haja vista que confere certa liberdade a seu autor.

Como foi dito no início deste texto, Notas de inverno... trata das viagens que Dostoiévski fez pela Europa no ano de 1862. Certamente, ao leitor mais atento, tal passagem pode ter parecido algo estranha. Afinal, a Rússia também integra o continente europeu. Com 
efeito, é no mínimo curioso mencionar a Europa como se a Rússia dela não fizesse parte. Tal tratamento nos remete à problemática identitária russa que nunca pôde ser definitivamente resolvida (mesmo nos dias de hoje). Confluência de diversas culturas, a Rússia é europeia, asiática ou um país único que precisa ser observado fora dos padrões geográficos e/ou geopolíticos que se apresentavam à época em que Dostoiévski produziu seu escrito? Não desenvolverei esse debate aqui, que por si só já mereceria um texto exclusivo em que poderíamos discutir as ideias eslavófilas e ocidentalistas à luz do século XIX. Por ora, lembremos apenas o que o próprio escritor diz a respeito do tema:

Somos realmente russos? Por que a Europa exerce sobre nós, sejamos quem formos, uma impressão tão forte e maravilhosa, e tamanha atração? [...] Toda a nossa vida se dispôs em moldes europeus, já desde a primeira infância. Será possível que algum de nós tenha podido resistir a esta influência, a este apelo, a esta pressão? Como foi que ainda não nos transformamos definitivamente em europeus? (DOSTOIÉVSKI, 2011, p. 79).

Nessa passagem, Dostoiévski explicita um sentimento comum do povo russo de então: o sentimento de não pertencimento à Europa. Talvez exatamente por isso a visão das modernas cidades europeias como algo "maravilhoso", especialmente Paris e Londres, tenha se arraigado de maneira tão profunda no "pensamento russo" daquela época. É notável que Dostoiévski não faça afirmações nessa passagem, mas apenas perguntas, o que demonstra que ele mesmo não era capaz de compreender como a Rússia não se tornara "europeia”, ou seja, como aquele país ainda não se tornara moderno. Em meados do século XIX, a Rússia era uma nação majoritariamente camponesa, e mesmo nas primeiras décadas do século XX o cenário não se modificara de maneira significativa. Angelo Segrillo (2012) observa que em 1913, não obstante o país figurasse como quinto maior produtor mundial da indústria bruta, isto é, um produtor industrial em grande escala, não havia hegemonia produtiva se se considerasse a produção per capita - um país pequeno como a Bélgica, por exemplo, possuía produção muito mais significativa para a sua economia interna do que a da grandiosa Rússia, cuja modernização somente se consolidaria, de fato, após a industrialização advinda da revolução bolchevique em 1917.

Sem dúvida, Paris e Londres foram as cidades que mais impressionaram Dostoiévski em suas viagens. A primeira representava um mundo justo no sentido estético do termo: a cidade perfeita na qual cada elemento parecia estar em seu lugar adequado; cidade que marchava harmoniosamente em um progresso contínuo (o que não deixa de ser visto com certa dose de ironia pelo escritor). Contudo, Dostoiévski não faz questão de esconder o espanto diante da grandeza da metrópole, capital cultural do mundo àquela época e que, ainda 
hoje, mantém esse status: "Sim, Paris é uma cidade assombrosa. [...] Realmente, mais um pouco e a Paris de um milhão e meio de habitantes vai transformar-se numa cidadezinha professoral e germânica, pretrificada em ordem e calmaria, a exemplo de alguma Heidelberg" (DOSTOIÉVSKI, 2011, p. 114). Assim, vê-se que o sentimento de Dostoiévski diante da Paris de meados do século XIX era de admiração e espanto. O caráter ambíguo desse sentimento se coaduna sobremaneira com o próprio conceito de modernidade que já observamos: algo que nos encanta devido a sua beleza alegórica, mas que, concomitantemente, se afasta de nós por uma espécie de exagero desproporcional que não somos capazes de mensurar. Para os "habitantes do século XXI" não é difícil gerenciar essa contradição. Mesmo que não estejamos nas cidades mais modernas do mundo, podemos saber como elas são e mesmo vê-las através dos recursos tecnológicos atuais. À época em que Dostoiévski escreveu suas notas, não havia como travar contato com as grandes metrópoles do mundo de maneira significativa senão indo até elas, o que certamente pode explicar o deslumbre que, em um primeiro momento, as cidades parecem ter provocado no escritor.

Mas se Paris impressionou o autor de Crime e Castigo por sua ordenação, ainda que esta se configurasse dentro de uma assombrosa e grandiosa megalópole, a cidade de Londres encantaria Dostoiévski por se tratar do extremo oposto:

\footnotetext{
Que diferença em relação a Paris, mesmo exteriormente! Esta cidade que se afana dia e noite, imensurável como o mar, com o uivar e ranger de máquinas, estas linhas férreas erguidas por cima das casas (brevemente, serão estendidas também por debaixo delas), essa ousadia de iniciativa, esta aparente desordem, que em essência é a ordem burguesa no mais alto grau... [...] Sente-se uma força terrível, que uniu num só rebanho todos estes homens inumeráveis, vindos do mundo inteiro (DOSTOIÉVSKI, 2011, p. 115).
}

Convém lembrarmos que na Inglaterra, durante os séculos XVIII e XIX, ocorreu a primeira grande revolução industrial. Enquanto Dostoiévski "flaneava" pelas ruas da capital inglesa, estava em curso um processo de industrialização que reconfiguraria a relação de trabalho na sociedade burguesa. Não é difícil entrever na passagem acima um olhar assustado diante do pretensioso progresso da modernidade. A grandiosidade da capital inglesa e a consequente impossibilidade de mensurá-la impressionam Dostoiévski. O olhar crítico do escritor russo observa que a ordem burguesa é, paradoxalmente, a ausência de qualquer ordenação. O espírito dessa nova sociedade que surgia diante de seus olhos se materializaria décadas depois, durante o século XX, com a consolidação do capitalismo. No entanto, já era possível perceber, no momento em que Dostoiévski escreve suas notas, que o "progresso" sobrepujara as construções humanas. As casas foram "invadidas" por linhas férreas; nas ruas, 
ouviam-se o ranger e o uivo das máquinas a vapor. Se naquelas turbulentas décadas alguém se trancasse em sua casa por um ano, após o que novamente ganhasse as ruas da grande cidade, provavelmente seria tomado pelo espanto e, talvez, fosse capaz de enxergar as transformações com os olhos de um estrangeiro, tal como os de Dostoiévski em suas viagens.

$\mathrm{O}$ relato de uma habitante da capital inglesa que, no início do século XX, também estava atenta à implacável ascensão da modernidade em Londres merece ser lembrado aqui. A comparação, ainda que sucinta, nos ajuda a verificar que os apontamentos feitos por Dostoiévski se consolidariam adiante de maneira inexorável. Em seu texto "A maré de Oxford Street”, Virginia Woolf (1882-1941) anota: “O encanto da moderna Londres está em ser feita para não durar, mas para passar. [...] Nós não edificamos para os nossos descendentes, que tanto poderão vir morar nas nuvens como debaixo da terra, mas para nós próprios e para as nossas necessidades" (WOOLF, 2005, p. 40-41). Nessa passagem, a escritora inglesa destaca a efemeridade londrina, em que nada é feito para durar, em que as coisas, as pessoas e as relações podem ser tão céleres quanto um trem sobre trilhos cortando o centro da cidade. $\mathrm{O}$ que Virgínia Woolf observa é a definição, hoje consolidada, das grandes metrópoles ocidentais. Assim, vemos que nas primeiras décadas do século XX, exato momento em que a romancista redigia seu texto, começava a se consolidar o conceito de modernidade na acepção baudelairiana: a bela mulher que anuncia o novo, mas que guarda em si os vestígios do passado; que nos ignora, mas a quem somos capazes de dedicar um poema.

De fato, seria impossível não perceber que, mesmo se apresentando como algo novo, nunca antes visto, a sociedade moderna não pode livrar-se totalmente dos elementos de um passado do qual se erigiu. Na cidade moderna, a contradição deve necessariamente estar presente. Referindo-se ao bairro High Market, escreve Dostoiévski: “É o bairro no qual, em algumas ruas, se acotovelam de noite milhares de mulheres da vida. [...] A cada passo, há magníficos cafés, com dourados e espelhos. Ali são os pontos de reunião e também de refúgio. Dá até medo penetrar nessa multidão" (DOSTOIÉVSKI, 2011, p. 119). Detrás das luzes ofuscantes e da beleza encantatória que cega o flâneur, observador atento, escondem-se as impurezas e imperfeições intrínsecas ao disforme mosaico da metrópole.

Outro aspecto de suma importância quando tratamos do surgimento das modernas cidades em meados do século XIX, diferentes quase em tudo daquilo com que nos habituáramos nos séculos anteriores, é a possibilidade de, em um mesmo espaço, coexistirem as mais díspares nacionalidades. Pessoas que antes jamais imaginaram se encontrar agora trocam cordiais apertos de mão. A propósito dessa temática, escreve Dostoiévski: 
Olham-se estas centenas de milhares, estes milhões de pessoas que acorrem docilmente para cá de todo o globo terrestre, pessoas que vieram com um pensamento único, que se aglomeram plácida, obstinada e silenciosamente neste palácio colossal, e sente-se que aqui se realizou algo definitivo, que assim chegou ao término (DOSTOIÉVSKI, 2011, p. 116).

O palácio a que o escritor faz referência, segundo Boris Schnaiderman, tradutor da edição brasileira de Notas de inverno..., era na verdade um grande edifício de vidro, com armação de ferro, construído em 1851, quando da Exposição Internacional de Indústrias. O que impressiona Dostoiévski não é somente a grandiosidade da obra arquitetônica, que seria destruída durante a Segunda Guerra Mundial, mas, especialmente, a heterogeneidade das pessoas que visitavam o local: “... em Londres pode-se ver a massa humana em tal dimensão e ambiente como não se encontra em parte alguma do mundo, a não ser em sonho" (DOSTOIÉVSKI, 2011, p. 117). Na assombrosa cidade europeia, milhares de pessoas de todo o mundo travavam contato umas com as outras já com alguma naturalidade, como se isso não fosse mais excepcional, mas algo corriqueiro em uma cidade desenvolvida como aquela. Sem dúvida, os novos meios de transporte, as vias férreas cujo nascimento fora ensejado pela modernidade tecnológica, permitiram um contato mais próximo entre pessoas e culturas antes tão distantes. Atentemos ainda, no trecho em destaque, para o que Dostoiévski diz sobre o Palácio de Cristal, onde "algo definitivo" acontecera. Ato contínuo nos perguntamos a que o escritor russo faz referência ao mencionar este "algo definitivo". Se considerarmos que o escritor russo se refere à direção que escolhemos seguir, a opção pelo moderno seria um caminho sem volta, o que hoje parece ser algo óbvio e indiscutível.

Nos capítulos finais de Notas de inverno..., Dostoiévski dará atenção especial às relações sociais surgidas com o advento da modernidade e a consequente modernização dos meios de produção. No Manifesto do Partido Comunista, Karl Marx (1818-1883) e Friedrich Engels $(1820$ - 1895) já haviam notado que todas as revoluções nos meios de produção implicam, necessariamente, transformações nas relações sociais entre os indivíduos (MARX; ENGELS, 2007). Sem afirmar que Dostoiévski está fazendo uma leitura calcada no pensamento do filósofo alemão, que não sabemos se chegou a ler, é interessante perceber como o escritor enxergava a figura do homem burguês nessa nova sociedade emergente em meados do século XIX: "Este burguês é uma pessoa estranha: proclama francamente que o dinheiro constitui a suprema virtude e a obrigação humana, e, ao mesmo tempo, gosta terrivelmente de aparentar a mais elevada nobreza de caráter" (DOSTOIÉVSKI, 2011, p. 128 129). Mais uma vez, o olhar de Dostoiévski desnuda uma contradição, desta vez de caráter. A partir do que nos diz o escritor, é possível compreender que o dinheiro como virtude humana 
não se coaduna com a nobreza de caráter que o burguês ambiciona exibir como mais um de seus incontáveis pertences. Portanto, o burguês é um sujeito essencialmente paradoxal e, por isso mesmo, um dos "melhores" representantes da moderna sociedade burguesa: "Acumular fortuna e ter o maior número possível de objetos transformou-se no principal código de moralidade no catecismo parisiense" (DOSTOIÉVSKI, 2011, p. 128). As características do parisiense do século XIX assemelham-se sobremaneira as dos habitantes de inúmeras capitais contemporâneas, já que a modernidade, embora tenha uma origem mais ou menos precisa, ainda não parece ter chegado ao fim nem é exclusiva de um único país ou cultura. A modernidade é, ao contrário, a desconstrução das diferenças entre as grandes metrópoles; verdade gritante para os dias de hoje. Com esforço, alguns buscam manter a arquitetura e cultura que diferenciam os espaços urbanos, mas estes desde há muito se assemelham em diversos aspectos. Os arranha-céus, as lanchonetes fast-food, o trânsito intenso de veículos e pessoas sempre atrasadas para seus compromissos, tudo isso parece fazer parte da genérica capital moderna que se configurava em meados do século XIX.

Considerando a crítica ao homem burguês empreendida por Dostoiévski, não seria despropositado acreditar que o escritor voltasse um olhar mais complacente ao pensamento oposto, o que significa dizer: ao pensamento de esquerda, socialista. Não é demais lembrar que o próprio Dostoiévski fora preso e condenado à morte por participar do círculo de Petrachévski, em que se discutiam ideias da esquerda socialista europeia, em especial as dos chamados socialistas utópicos como Charles Fourier (1772-1837) e Saint-Simon (1760-1825). Entretanto, as observações presentes em Notas de inverno... não são nada condescendentes em relação aos socialistas: “... o que pode fazer o socialista, se o homem ocidental não possui o princípio fraterno, e se, pelo contrário, o que existe nele é um princípio individual, pessoal, que se debilita incessantemente, que exige de espada na mão os seus direitos?" (DOSTOIÉVSKI, 2011, p. 136). Aqui, merece destaque o fato de que, na visão de Dostoiévski, nem o burguês com sua sociedade liberalizante, nem o socialista pregando uma suposta igualdade entre os indivíduos poderiam superar as contradições do homem daquele tempo, já de todo afetado por um novo mundo que via erguer-se diante de si.

Os três capítulos finais de Notas de inverno... são dedicados a uma explanação teórica acerca das sociedades europeias que Dostoiévski então visitava. Em lugar das descrições urbanas que observamos anteriormente, o texto passa a abordar questões de caráter filosófico. Porém, é forçoso voltarmos uma vez mais aos relatos sobre a metrópole física, pois não ficou claro por que podemos considerar Dostoiévski um verdadeiro flâneur da ascendente 
modernidade. Naturalmente, é preciso que relativizemos a questão, já que o escritor russo não se enquadraria no estereótipo de flâneur descrito por Walter Benjamin: "A rua se torna moradia para o flâneur que, entre as fachadas dos prédios, sente-se em casa tanto quanto o burguês entre suas quatro paredes" (BENJAMIN, 1995, p. 35). Se consideramos tal característica destacada pelo filósofo alemão, a de um sujeito que se compraz em vaguear em meio a uma cidade cujos prédios cada vez mais ocupam o espaço azul do céu, não poderemos chamar Dostoiévski de "flâneur clássico", tendo em vista que as observações do escritor russo demonstram a lucidez de um sujeito atento ao que o circunda. $\mathrm{O}$ que diferencia as notas do romancista russo é seu olhar crítico, que não se contenta em apenas descrever imparcialmente aquilo que vê, como alguém que escreve para um jornal. Havia a necessidade, por parte de Dostoiévski, de relatar as sensações, as experiências pessoais de sua viagem, daí o caráter pouco organizado do texto, daí também as "escusas iniciais" com que o escritor principia a obra. E que nesta não se queira encontrar a verdade sobre o que acontecia naquele suntuoso mundo em que a Rússia gostaria de se ver transformada. Aos que estiverem dispostos a ler uma versão da história, Notas de inverno... poderá ter alguma serventia, eis o que Dostoiévski nos anuncia desde o início.

Partindo de suas desorganizadas anotações sobre as cidades pelas quais passa, Dostoiévski se permite abordar temas filosóficos e políticos, já nos capítulos finais do texto. Tais debates não deixam de ter relação direta com as metrópoles modernas da Europa, haja vista que era no "velho mundo" onde se debatiam calorosamente algumas das questões mais importantes da filosofia daquele tempo. Em alusão à Crítica da razão pura, por exemplo, escreve Dostoiévski:

[...] a razão revelou-se inconsciente ante a realidade e, além disso, os próprios homens de razão, os próprios sábios, começam a ensinar agora que a razão pura nem existe no mundo, que não existem as conclusões da razão pura, que a lógica abstrata é inaplicável à humanidade, que existe a razão de Ivan, de Piotr, de Gustave, mas que a razão pura nunca existiu; que tudo isto não passa de uma invenção do século XVIII, destituída de fundamento (DOSTOIÉVSKI, 2011, p. 131).

Na passagem acima, destaca-se a menção feita ao século XVIII. A propósito do pensamento filosófico de Immanuel Kant (1724-1804), observamos em Dostoiévski a consciência de que certa concepção que se tinha a respeito da razão entre os homens era algo passado e, portanto, já não poderia mais ser a do homem do século XIX, isto é, a do homem moderno que então se edificava. Essa passagem de Notas de inverno... é emblemática, uma vez que apresenta de maneira muito clara a liberdade que o homem do "novo mundo" emergente via diante de si. O "novo homem" moderno, aparentemente livre, seria capaz de 
criar maravilhas que superariam de longe as pirâmides do Egito e os aquedutos romanos, para citar Marx e Engels ainda uma vez (MARX; ENGELS, 2007). Todavia, há que recordamos das contradições intrínsecas ao conceito de modernidade abordado em princípio. Contradições que não passam ao largo das Notas de inverno sobre impressões de verão, em que não lemos apenas um relato descritivo, mas uma visão crítica e ácida de algumas das principais capitais do mundo. Com efeito, a despretensiosa obra de Dostoiévski é um interessante retrato, em cores vivas, de um tempo que não vivemos in loco, mas do qual somos herdeiros desgarrados.

\section{Referências}

BAUDELAIRE, Charles. Les fleurs du mal. Paris: Librio, 2011.

. As flores do mal. Tradução, introdução e notas de Ivan Junqueira. Edição bilíngue. Rio de Janeiro: Nova Fronteira, 1985.

BENJAMIN, Walter. Obras escolhidas III - Charles Baudelaire - um lírico no auge do capitalismo. São Paulo: Brasiliense, 1995.

DOSTOIÉVSKI, Fiódor. O crocodilo e Notas de inverno sobre impressões de verão. $4^{\mathrm{a}}$ ed. Tradução de Boris Schnaiderman. São Paulo: Editora 34, 2011.

JAUSS, Hans Robert. La modernité dans la tradition littéraire et la conscience d'aujourd'hui. In: . Pour une esthétique de la réception. Paris: Gallimard, 1978. p. 173-220.

SEGRILLO, Ângelo. Os russos. São Paulo: Contexto, 2012.

MARX, Karl; ENGELS, Friedrich. O manifesto comunista. Tradução de Maria Lucia Como. Rio de Janeiro: Paz e Terra, 2007.

WOLLF, Virgínia. A maré de Oxford Street. In: Londres. Tradução de José Miguel Silva. Lisboa: Relógio d'Água, 2005.

[Recebido em janeiro de 2016 e aceito para publicação em abril de 2016]

Russian impressions of the modernity: Dostoyevsky traveling through Europe

Abstract: in the present study, I analyze the non-fictional text written by Fyodor Dostoyevsky (1821-1881) during his travels through Europe in 1862, Winter notes on summer impressions (1863) - work apparently unpretentious and that does not obey the formal rigor of any specific literary genre. At first and briefly, it matters to me highlight the origin of the word "modernity" in light of the etymological research of this term undertaken by the German theorist Hans Robert Jauss (1921-1997) and the conception elaborated by the French poet and critic Charles Baudelaire, especially in his poem $\grave{A}$ une passante. Subsequently, some of the main excerpts from Winter notes... regarding the physical descriptions of the cities will be commented to emphasize, mainly, the critical look with which Dostoyevsky viewed the 
transformations that were undergoing in Europe (notably the capitals Paris and London) during the second half of the nineteenth century.

Keywords: Dostoyevsky. Modernity. Europe.

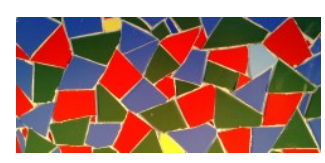

